of this work is what Wigner called "the unreasonable effectiveness of mathematics". Wigner was referring to the mysterious phenomenon in which areas of pure mathematics, originally constructed without regard to application, are suddenly discovered to be exactly what is required to describe the structure of the physical world. Thus, Riemann's general formulation of the geometry of curved spaces was essential to Einstein's understanding of gravity; Heisenberg found that the symbolic arrays which in quantum mechanics represent observable quantities were the matrices that had been invented decades earlier; and now recondite aspects of the distribution of prime numbers might well provide the link between quantum mechanics and newtonian chaos.

Such connections raise many questions. Is mathematical truth invented by mathematicians, or does it already exist in the world, to be discovered when our minds become sophisticated enough? If discovered, where is it beforehand? What is its relation to the matter whose behaviour it describes so well? Is there any inapplicable mathematics?

Barrow does not answer these questions, but gives a careful and perceptive account of their background and the philosophies they have stimulated. He starts, appropriately enough, with an anthropological and historical analysis of counting and calculation, focusing on the tricky question of whether such skills are innate, and would inevitably develop in any human society, or whether they arose 'accidentally' in one (or several) societies, and diffused to the others. The latter is, he thinks, more plausible. Central here are the inventions (discoveries?) of place values and of zero, by the Babylonians and Hindus 5,000 years ago, leading via the mediaeval Arabs to the decimal system we use today.

Because mathematics is the most precise embodiment of systematic thought, it was natural to try to prove that it has a solid foundation in logic and is perfectly consistent. The story of these attempts has often been told. How Frege, Russell and Whitehead tried to 'derive' mathematics from logic almost a century ago, and how this attempt was complicated by the irritating paradoxes of selfreferential sets ('If the barber shaves everyone who does not shave himself, who shaves the barber?'). How Hilbert took up the challenge by trying to prove the consistency of mathematics from within, by formalizing its symbols and deductive steps. How "all the noonday brightness of this confident picture of the formalists' little mathematical world was suddenly extinguished" by Gödel's proof in 1931 that the set-theory paradoxes make it impossible for a sufficiently complicated system to be proved consis- tent from within. These ideas are central to modern notions of randomness as the inability to compress information, and may have implications for our attempts (in my view doomed) to find a compact encoding of the physical universe as a 'theory of everything'. Barrow's account of these matters is lucid and engaging.

After pointing out that "formalism is lacking in two crucial respects" (it does not explain the usefulness of mathematics and its relation to the minds of mathematicians), Barrow turns to inventionism. This "amounts to the claim that mathematics is a branch of ... psychology". It makes "mathematical truth dependent upon time and history", and "one cannot help but feel that humanity is not really clever enough to have "invented" mathematics".

A chapter is devoted to Brouwer's programme of intuitionism, where the natural numbers are regarded as unarguably 'given', and the aim is to build the rest of mathematics "by step-by-step deductions using a finite number of steps". This brought him into collision with Hilbert, who believed that such a philosophy, which disallowed infinite processes such as arguing by reductio ad absurdum, would fatally impoverish and weaken mathematics. Hilbert's attempt to enforce political correctness and to expel Brouwer from the editorial board of Mathematische Annalen provoked an absurd and bitter controversy that Einstein called the "war of the frogs and mice".

Finally, Barrow explores the Platonic position that mathematical abstractions exist "in a realm of non-spatial, nonmental, timeless entities". He concludes, albeit somewhat uneasily: "Our ability to create and apprehend mathematical structures in the world is merely a consequence of our own oneness with the world".

I admit to finding some of Barrow's arguments hard to follow not because of their content but because of his habit of using very long sentences unadorned by punctuation whose verbs are hard to find and whose meanings therefore hard to unravel. Worse, some sentences are incomplete, and there are many spelling mistakes. Quotations abound. Some are witty and apposite, but why propagate Spiro Agnew's abysmal "An intellectual is a man who doesn't know how to park a bike"?

These are, however, minor criticisms, and I warmly recommend Barrow's brave attempt to gather up the many loose threads of this elusive subject - a subject so central to our scientific culture - and to grasp the whole of it.

Michael Berry is in the Department of Physics, University of Bristol, Bristol BS8 1TL, UK.

\section{Einstein as lover}

\section{Joseph Schwartz}

Albert Einstein and Mileva Marić: The Love Letters. Edited and with an introduction by Jürgen Renn and Robert Schulmann. Translated by Shawn Smith. Princeton University Press: 1992. Pp. 107. \$14.95, £12.50.

THIS elegantly published volume of letters between the young Einstein and the young Marić is a spin-off from the first two volumes of a planned 35 volumes containing some 43,000 documents lying in the Einstein archive. A lovely introduction by Jürgen Renn and Robert Schulmann, coeditors of the project, draws our attention to the unique personality of Marić and her central contribution to the Einstein success story. The meticulous scholarship of the notes is wonderful, particularly the inclusion of the dates of virtually all the characters in this first act of the Einstein drama. And the letters themselves are a treat, a window into the early development of the man who became the most celebrated scientist in history. But what, when all is said and done, does this correspondence tell us?

The Einstein we see here is bubblingly optimistic, reassuring, high-spirited, confident about life. For the first time we have an Einstein with sexuality: "Oh my! That Johnnie boy!/So crazy with desire/ While thinking of his Dollie/His pillow catches fire" (letters 19); "How beautiful it was the last time you let me press your dear little person against me in that most natural way" (letter 33). Albert is happy in his sexual relationship with Marić and the letters show it.

There is a not entirely happy story here, however, about two lovers, one who thrives, the other who gets increasingly submerged by life. We meet them both as students of physics. She, a late entrant from the distant provinces of undeveloped Serbia, is three-and-a-half years his senior. He is youthful, exuberant. No obstacle is too great. She, while available for emotional and sexual involvement, is unhappy, feeling that her provincial background has irreversibly limited her chance in physics. While Einstein is absorbing with great fascination the nuts and bolts of doing physics, Marić is distant, observing wistfully the spectacle of her university lecturers: "human beings are so clever and have accomplished so much as I have observed once again here in the case of the Heidelberg professors" (letter 1).

As we journey with these lovers over a 
period of five years, we see Marić becoming more unsure of herself, unsure of her place in Einstein's life, pregnant, carrying their illegitimate child on her own while Einstein is employed elsewhere, giving birth without him being there and painfully giving up the baby Liserl for adoption. The letters end with Marić pregnant again, Einstein working at his job in the Swiss patent office, her worried that he will be angry about her being pregnant, he reassuring her: "I'm not the least bit angry that poor Dollie is hatching a new chick. I'm happy about it and had already given some thought to whether I shouldn't see to it that you get a new Liserl. After all you shouldn't be denied that which is the right of all women" (letter 54).

One gets the unmistakeable impression that Einstein grew stronger through his relationship with Marić while she increasingly felt weakened and despairing. There is a deep melancholy in this picture of Einstein's life before he became a star.

Like most collections of letters of leading public figures, these are well worth reading. But we must ask: what are we doing delving into Einstein's love life? Aren't we like Madonna fans, fascinated by our star's stardom? Do these letters tell us what we really want to know?

To understand Einstein we need to understand stardom. We need not the Einstein papers but the newspapers. What has been the role of the media in creating the Einstein legend? What have we been responding to in this myth of the man without socks, the mysterious icon of pure thought? These letters show that, like the luminiferous ether, the Einstein we seek does not exist except in our minds. The mystery of Einstein is the way we have made him incomprehensible. Einstein's achievement, a masterpiece of human understanding, has been turned on its head to become a symbol for the impossible to understand. How did this happen?

Joseph Schwartz is at 2 Lancaster Drive, London NW2 4HA, UK.

\section{Scientism disguised?}

\section{John Polkinghorne}

The Unnatural Nature of Science: Why Science Does Not Make (Common) Sense. By Lewis Wolpert. Faber and Faber: 1992. Pp. 191. £14.99, $\$ 22.95$.

THE unnaturalness of science is held to lie both in the superior clarity of its thought over everyday notions (exemplified, for instance, by common-sense misapprehensions about probabilistic reasoning) and in the counterintuitive character of regimes far from common experience (such as the quantum world). This unnaturalness is to be commended, and Lewis Wolpert's book is a kind of hymn of praise from one of science's practitioners. He rightly distinguishes science from technology, characterizing the scientific aim as the understanding of the world, not its manipulation. It all started in Greece, but Wolpert acknowledges that an essential development occurred in seventeenth-century Europe with the turn to empirical investigation. $\mathrm{He}$ is sufficiently candid to recognize that there was religious encouragement to regard the world as rationally structured, but he fails to notice that the idea of the Creator's freedom of action, enshrined in the Judaeo-Christian-Islamic tradition, implied that one had actually to look to see what order He had chosen to create.

Wolpert is good about scientific creativity, recognizing that it requires a to a guest who is entertaining, slightly relentless and - let's face it - a mite opinionated. The superiority of science is ruthlessly asserted. "Scientific knowledge is special and privileged - in the sense that it provides our best understanding of the world." One cannot deny that science provides our best understanding of some aspects of the world, but its success is purchased by the limitation of its ambition. Essentially it is concerned only with certain kinds of impersonal, largely repeatable experience. But a painting is much more than a collection of specks of paint of known chemical composition, and there is a great deal more to human experience than science is able to tackle. Wolpert makes the astonishing mistake of equating the method of investigation with the actual nature of reality. $\mathrm{He}$ says, "Any philosophy that is at its core holistic must tend to be anti-science, because it precludes studying parts of a system separately".

Even within science, it is absurd to adopt such a reductionist stance. What if there are holistic laws of nature, such as organizing principles working in the direction of increasing complexity? They will have to be sought through new methodologies, but our concern as scientists must be to respond adequately to the way the physical world actually is. In fact, twentieth-century physical science has seen the death of mere mechanism and the discovery of an interconnectedness (nonlocality) in the fabric of the world.

Wolpert is at his worst when he speaks of religion. There is an assertive dismissiveness ("religious belief is incompatible with science"), derived from a caricature picture ("religion is based on unquestioning certainties"). His treatment of theological thought is as crude an abuse as is the creationists' misuse of scientific thought. Wolpert acknowledges with Tolstoy that "science does not tell us how to live". His answer to moral issues seems to be ultimately the social endorsement of the vox populi. Yet his sensitive discussion of the mistakes of the eugenics movement shows that he would not have accepted such policies even if they were endorsed by society (as they were in Nazi Germany). He should think a bit more about what is the source of our intuition of the value of human individuals.

Beneath the civilized discourse of this entertaining book there is a note of unconscious arrogance. The science is tinged with scientism ('science is all') in a way that fuels the fires stoked by the likes of Brian Appleyard or Mary Midgley.

John Polkinghorne is President of Queens' College, Cambridge CB3 9ET, UK.

NATURE · VOL 360 - 26 NOVEMBER 1992 